unavoidable criticism. Had the author lived to complete his work, such omission would doubtless never have occurred. His realistic grasp of basic principles, so evident throughout, would have been enriched by this more spatial survey of their applications.

The book is reasonably documented, but lacks an index. The editors are commended for the discharge of a difficult task. For that reason, apart from perpetuating the name of such a brilliant geologist as the author, this volume deserves success; it should be in every library embracing the literature on petroleum. H. B. MILNER

\section{SOUNDING ROCKETS}

\section{Sounding Rockets}

By Homer E. Newell, jun. (McGraw-Hill Series in Missiles and Space Technology.) Pp. vii +334 . (London: McGraw-Hill Publishing Co., Ltd., 1959.) $97 s$.

7 HE use of sounding rockets for making scientific measurements in the Earth's upper atmosphere first gained world-wide attention during the Inter. national Geophysical Year, when some 200 rockets were launched by the United States alone. However, experiments of this kind began more than ten years earlier and a wide variety of research rockets and adaptations of military rockets have since been used for research purposes. Scientific conferences on the new techniques and results have gradually become widespread, and this book grew out of papers given at one such symposium organized by the American Rocket Society during November 1956. It is the work of almost a score of collaborators under the general editorship of Dr. Newell, who is now the assistant director for space sciences in the U.S. National Aeronautics and Space Administration.

Most of the book is devoted to descriptions of sounding rockets developed by France, Japan, the United Kingdom and the United States. The history of the development, and details of the propulsion system, construction features and launching methods, together with performance details are given in almost all cases. There are chapters on balloon- and aircraft-launched rockets, including a few figures of costs, and on the range facilities available for rocket firings. The book is copiously illustrated by photographs and diagrams with numerous references and a reasonable index. A final short chapter on Earth satellites is written by Dr. Newell, but does little more than list some of the experiments such vehicles make possible and give a brief account of basic orbital characteristics.

The details of the various rocket vehicles will be of value to workers engaged in the design of such devices, and much previously inaccessible information is usefully gathered together. The account of the physical properties of the high atmosphere and of the ionosphere, aurora, cosmic radiation, airglow, magnetic field, etc., given in Chapter 2 is so highly condensed that what might otherwise have been one of the most interesting parts of the book seems likely to please neither the specialist nor the newcomer to the subject. In contrast to the careful listing of firing procedures and geographical location of firings completed, the extremely brief description of the results achieved and of the apparatus used for the measurements is very disappointing, although the interested reader could no doubt find much informa. tion among the hundred or more references listed throughout the book. Despite these criticisms, the book can be recommended as a useful history of the many rockets used for upper atmosphere research during the past decade and a guide to the pay-load and performance capabilities of the various types.

W. H. STEPHENS

\section{POISONOUS AMPHIBIANS AND REPTILES}

\section{Poisonous Amphibians and Reptiles}

Recognition, and Bite Treatment. By Prof. Floyd Boys and Prof. Hobart M. Smith. Pp. xiii +149. (Springfield, Ill.: Charles C. Thomas; Oxford : Blackwell Scientific Publications, 1959.) 368.

GORTUNATELY it is fairly uncommon to find 4 present-day authors of scientific books prone to the worst style of pompous and woolly writing'gobbledygook' - for the great majority do produce works that are both factual and concise.

Although the term 'gobbledygook' was coined in the United States, not all its citizens, evidently, have yet learned to avoid writing jargon, and Boys and Smith's book is considerably marred by its phraseology and ambiguity. One of their prime examples of obfuscation is, "If the site of the bite is such that there are no anatomical contraindications to the suggested maneuver ...". The book is intended primarily as a practical manual for the recognition of poisonous reptiles and amphibians and for first-aid treatment of bites; but the average person, particularly in an emergency, would surely grasp more quickly the advice "call a doctor" than ". . . the best procedure is to request an immediate house call there by the physician contacted".

Much extraneous material has crept in, and some relevant matters have been omitted. An account of snake locomotion and rattles, for example, is out of context, while two frogs reputedly poisonous are not named, being merely described as red-legged, one occurring in the eastern and one in the western United States. Presumably the eastern one is Rana palustris, the pickerel frog, and the other is Rana aurora, the red-legged frog, yet examples of the first species are often yellow or orange coloured on the thigh, not red. Incidentally, the inference in the description is that only one species is involved.

The book purports to be limited in scope to those species occurring in and around North America, yet the species of 'common toad' figured is a British natterjack. Mention is also made of the extreme caution with which the South African boomslang should be handled-a good point, however, in view of the tragic death of the doyen herpetologist, Dr. K. P. Schmidt, and of the flippant manner in which many persons handle rear-fanged snakes.

In the section dealing with first aid, the use of potassium permanganate crystals is rightly decried. In earlier works, this substance was invariably recommended as suitable treatment for snake bites, but it was later found to have deleterious effects and is therefore now omitted from snake-bite kits.

The authors do not tread new ground by producing this book but instead have collated and revised previous texts on similar subjects and assembled the information as a unit. $\quad$ A. G. C. GRandison 